\title{
Compliance of Anti-Retroviral Therapy among 250 HIV Infected Persons in a Tertiary Level Hospital in India
}

\author{
K. Raadhika ${ }^{1}$, R. Navajothi ${ }^{2}$, Sabari Raj ${ }^{3}$ \\ Associate Professor, Institute of Pharmacology Madurai Medical College, Madurai \\ Associate Professor, Department of Pharmacology Govt.Sivagangai Medical College, Sivagangai \\ Under Graduate Student Madurai Medical College, Madurai
}

\begin{abstract}
Background: AIDS is a disease which in the present era has gained utmost importance owing to both its prevalence and also fatality. This study aims at determining the compliance of therapy and the clinical profile used as an aid to draw conclusions for various reasons of non compliance. Aim and objective: To determining the compliance level of HIV patients undergoing Anti-Retro Viral Therapy and reasons for non-compliance. Materials and Methods: A detailed structured Questionnaire was prepared to analyse the compliance of 250 patients receiving ART from the ART centre of a tertiary level hospital.. The data collected are analyzed using Chisquare test, Student $t$ test and the proportion tests. Results : Out of 250 patients $74 \%$ patients showed $100 \%$ compliance level(p<0.001). In males $73.82 \%$ were $100 \%$ compliant and in females $74.25 \%$ were $100 \%$ compliant. $69.59 \%$ employed were compliant and $91.13 \%$ unemployed were compliant.. $71.73 \%$ illiterate were compliant, The family income per month $\leq 1000$ are $100 \%$ compliant; $\leq 5000$ 71.51\% were compliant; $\geq 5000-72.41 \%$ were compliant. Patients who had travelled a distance of only $\leq 10$ kms were $87.35 \%$ compliant; a distance of 11-50 kms of which $72.38 \%$ were compliant, a distance of $>50 \mathrm{kms} 41.37 \%$ were compliant. Conclusion: The results of our study revealed that a compliance of $74 \%(185 / 250)$ which was affected by a number of socio-economic and physical reasons. The compliance can be increased by repeated counselling to both the patient and the family members and to high risk groups.
\end{abstract}

Keywords: Antiretroviral therapy, Complaince, Psycho-social factors, Adherence to Antiretroviral therapy

\section{Introduction}

India has 2.1 million people living with HIV,the third largest population of people infectd with HIV/AIDS according to UNAIDS Gap report 2014. (23.9 lakh people as per the 2008-2009) ${ }^{1}$.Advances in Anti retroviral therapy( ART)and HAART (Highly Active Anti Retroviral Therapy) over the last 15 years have led to dramatic changes in the prognosis, quality of life and management of people living with HIV and AIDS in both resource rich and resource limited environment. The main drugs given are Nucleoside Reverse Transcriptase Inhibitors (NRTIS)- Zidovudine, Lamivudine, Stavudine etc, and Non-Nucleoside Reverse Transcriptase Inhibitors (NNRTI'S) -Nevirapine and Efavirenz. Combinations of these provide with different regimens for ART.

ART is useful in prolonging and improving the quality of life and postponing the complications of AIDS or AIDS related complex (ARC), Since none of the regimen can eradicate HIV from the body of the patient, the goal of the therapy is to inhibit the viral replication.

A study conducted by Dr.Ajay K Sethi etal 3,concluded that poorer compliance is associated with treatment failure ,but not necessarily resistance. Thus a very high compliance level is required for the success of the treatment.

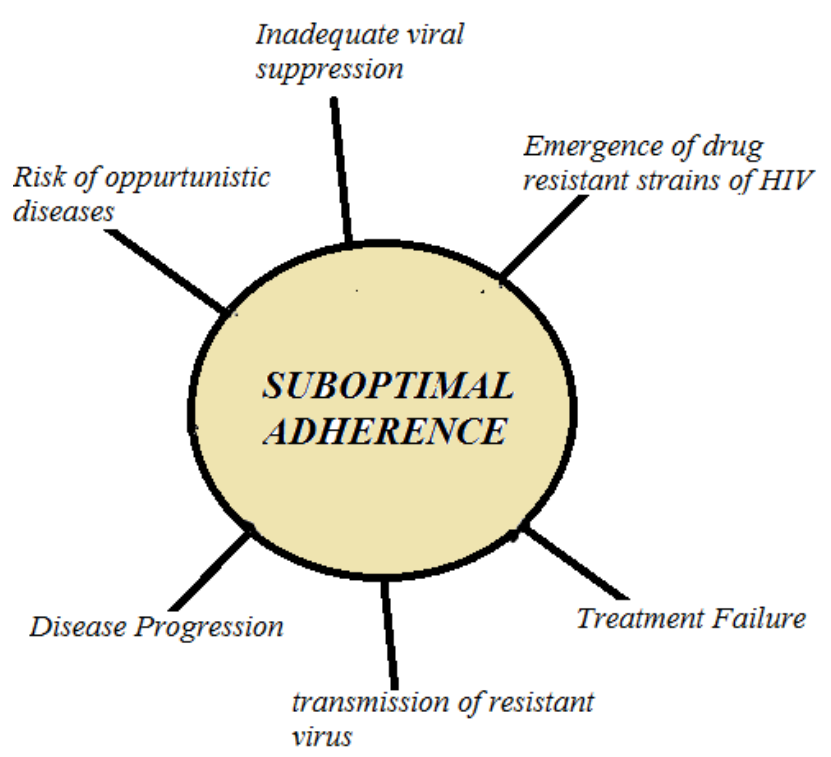

This study focuses on determining the compliance of patients receiving Anti-Retroviral Therapy in a tertiary level hospital in India and various reasons for the lower compliance.

\section{Aims and Objectives}

This study aims at determining the compliance level of HIV patients undergoing Anti-Retro Viral Therapy and evaluate various reasons for non-compliance calculated. 


\section{Materials and Methods}

- Study design: Observational Randomized questionnaire study.

- Type of study: Prospective study.

- Site of study: Outpatient Department, ART centre, Government Rajaji Medical College Hospital, Madurai, Tamilnadu.

- Duration of study: 2 months.

- Sample size: 250 subjects.

\section{Methodology}

A prospective study of about 250 patients receiving ART from the ART centre of a tertiary level hospital is to be conducted and their compliance to therapy is evaluated. The patients are selected intermittently but consecutively during the morning office hours.

\section{Inclusion Criteria}

1) The patient should be receiving the medication for atleast a period of 1 year.

2) Patient should be18 years or older.

3) Patients of both sexes are evaluated.

4) Patients receiving only two regimens $A$ and $B$ are selected.

\section{Regimen A}

Tab. Stavudine 300mg

Tab.Lamivudine150mg

Tab.Nevirapine200mg

\section{RegimenB}

Tab.Zidovudine 300mg

Tab.Lamivudine150mg

Tab.Nevirapine200mg

\section{Exclusion Criteria:}

1) Patients are excluded from the study if they have an active illness or unaware of their HIV infection status.

2) Pregnant ladies are exempted.

\section{Confidentiality}

Personal information's like contact address or telephone numbers are not collected and confidentiality maintained. Informed consent form is given to all patients that states all the essential details related to the study. They are asked to read the informed consent before the start of study and get sign from them.

\section{Ethical Considerations}

As the study includes human participants, a clearance from the Institutional ethics committee (IEC) is obtained.

\section{Procedure}

The selected patients are interviewed personally using a questionnaire which deals with the personal history of the patient and also his status in receiving antiretroviral therapy. The patient history includes the basic details of the patient along with details like family size, income, marital status, substance use etc. The later part of the questionnaire focuses on the various aspects of Antiretroviral therapy. Details of drug regimen, food ,frequency of drug intake and visit to the
ART center, difficulties in continuing therapy, social support, alternative therapies ,counselling, health care satisfactions etc are analyzed.

Compliance is calculated by directly asking the patient whether they have taken the medications regularly at proper time and intervals for the past 1 month, on the advice of doctor. Percentage of adherence is calculated on the basis of above compliance. Similarly follow up adherence is calculated for past 1 year and since HIV infection was detected. Low compliance are calculated as those who are having adherence level of less than $100 \%$.ie missing even a single dose can render a patient non-compliant. The major factors which contribute to low compliance are finally enquired and correlated with their personal and clinical history.

\section{Statistical Analysis}

The data collected are analyzed using Chi-square test,Student $\mathrm{t}$ test and the proportion tests.

\section{Observations and Results}

250 HIV positive patients on Antiretroviral therapy (ART) have agreed to give consent for analysis of adherence to ART. They were interviewed using a questionnaire at ART centre. Out of 250 patients,185(74\%) patients showed 100\% compliance level $(\mathrm{p}<0.001)$.Remaining $26 \%$ were not $100 \%$ compliant.(Table 1,Figure 1)

Table 1:

\begin{tabular}{|c|c|c|}
\hline Total & Compliant & Non- Compliant \\
\hline 250 & $185(74 \%)$ & $65(26 \%)$ \\
\hline
\end{tabular}

\section{Compliance to ART}

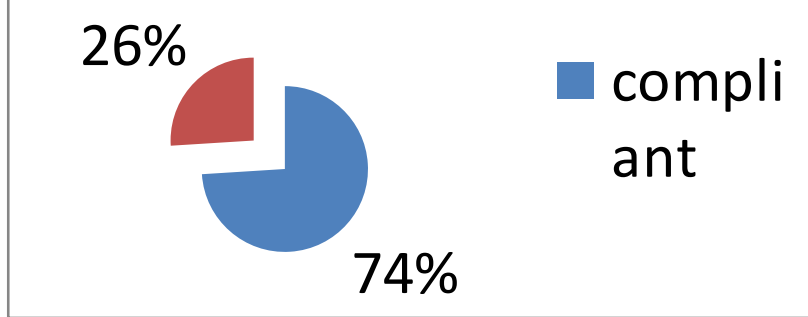

Figure 1

Out of 250 patients 149(59.6\%) were males and 101(40.4\%) were females. In males $110(73.82 \%)$ were $100 \%$ compliant and in females $75(74.25 \%)$ were $100 \%$ compliant. Compliance is equal in both gender. The data had no significance on statistical analysis. (Table2)

Table 2

\begin{tabular}{|c|c|c|c|}
\hline & Total & Compliant & Non-Compliant \\
\hline Male & $149(59.6 \%)$ & $10(73.82 \%)$ & $39(26.17 \%)$ \\
\hline Female & $101(40.4 \%)$ & $75(74.25 \%)$ & $26(25.74 \%)$ \\
\hline
\end{tabular}

$66(26.4 \%)$ patients belonged to $18-34$ age group, and out of these 56(84.84\%) were found to be compliant.160(64\%) belonged to 35-49 age group in which 111(69.37\%) were found to be compliant.24(9.6\%) belonged to $\geq 50$ age group 


\section{International Journal of Science and Research (IJSR) \\ ISSN (Online): 2319-7064 \\ Index Copernicus Value (2013): 6.14 | Impact Factor (2015): 6.391}

which reported $87.5 \%$ (21 subjects) compliance. compliance was more in older age group.(Table3,Figure 2)

Table 3

\begin{tabular}{|c|c|c|c|}
\hline Age group & Total & Compliant & Non-Compliant \\
\hline $18-34$ & $66(26.4 \%)$ & $56(84.84 \%)$ & $10(15.16 \%)$ \\
\hline $35-49$ & $160(64 \%)$ & $111(69.37 \%)$ & $49(30.63 \%)$ \\
\hline$\geq 50$ & $24(9.6 \%)$ & $21(87.5 \%)$ & $3(12.5 \%)$ \\
\hline
\end{tabular}

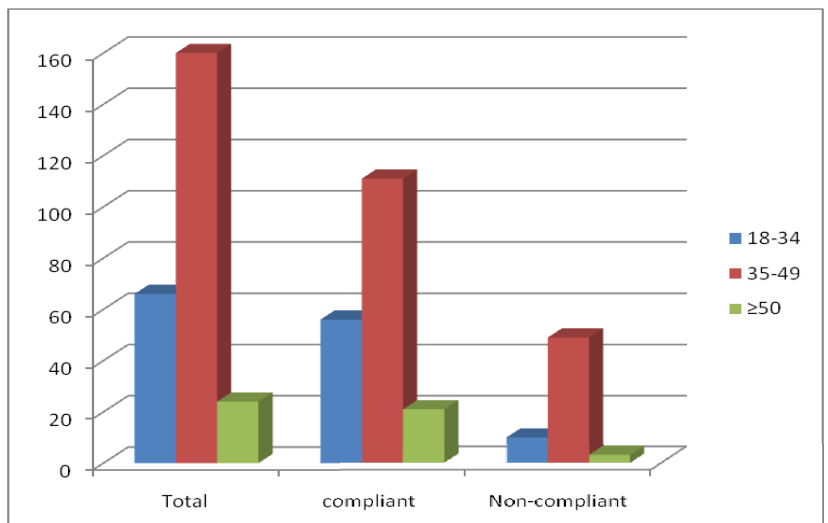

Figure 2

Of the 250 patients, $171(68.4 \%)$ were employed of which 119(69.59\%) were compliant and 79 were unemployed of which $72(91.13 \%)$ were compliant. Compliance has no relation to employment status. The data had no significance on statistical analysis. $(\mathrm{p} \geq 0.01)$

46(18.4\%) subjects were illiterate of which 33(71.73\%) were compliant, 63(25.2\%) had primary education of which 54(85.71\%) were compliant, 132 had secondary education of which 93(70.45\%) were compliant and 9(3.6\%) had studied beyond XII of which 5(55.55\%) were compliant. The data had no significance on statistical analysis. $(p \geq 0.01)$.

The family income per month was $\leq 1000$ for $20(8 \%)$ subjects,all(100\%) being compliant; $\leq 5000$ for $172(68.8 \%)$ of which $123(71.51 \%)$ were compliant; $\geq 5000$ for $58(23.2 \%)$ of which $42(72.41 \%)$ were compliant. The economical status had no significant role in compliance ( $\mathrm{p} \geq 0.01)$.

87(34.8\%) patients had to travel a distance of only $\leq 10 \mathrm{kms}$ of which $76(87.35 \%)$ were compliant;134(53.6\%), a distance of 11-50 kms of which 97(72.38\%) were compliant and 29 had to travel a distance of $>50 \mathrm{kms}$ out of which only 12(41.37\%) were compliant. (Table 4,Figure 3). A significant association was noted between compliance and the distance from the ART centre $(\mathrm{p} \leq 0.001)$

\section{Table 4}

\begin{tabular}{|c|c|c|c|}
\hline $\begin{array}{c}\text { Distance from ART } \\
\text { center }\end{array}$ & Total & Compliant & Non-Complaint \\
\hline$\leq 10 \mathrm{kms}$ & $87(34.8 \%)$ & $76(87.35 \%)$ & $11(12.64 \%)$ \\
\hline $11-50 \mathrm{kms}$ & $34(53.6 \%)$ & $97(72.38 \%)$ & $37(27.61 \%)$ \\
\hline$>50 \mathrm{kms}$ & $29(11.6 \%)$ & $12(41.37 \%)$ & $17(58.62 \%)$ \\
\hline & $\mathrm{P}<0.001$ & & \\
\hline
\end{tabular}

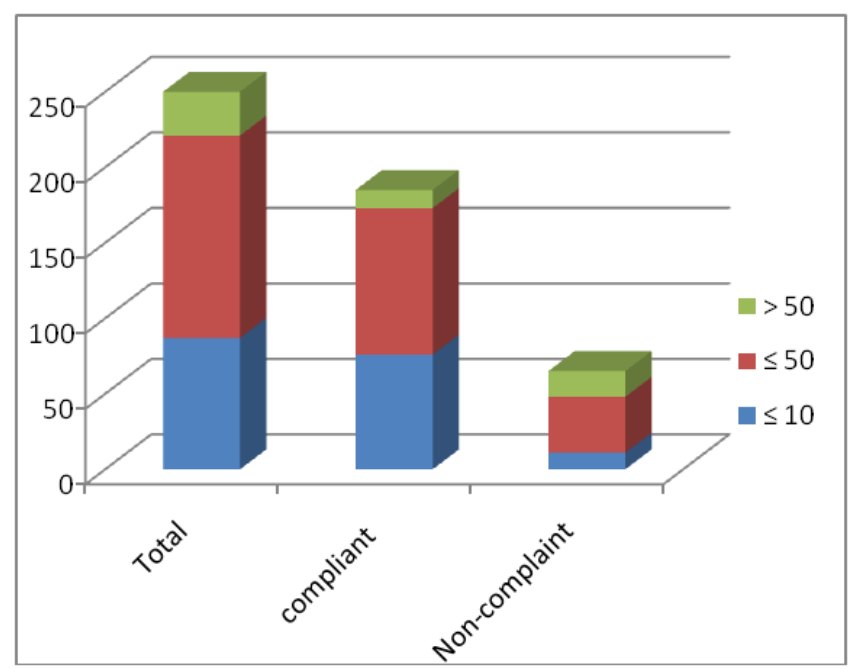

Figure 3

Of the 250 patients 16(6.4\%) were single,7(2.8\%) were divorced or separated,67(26.8\%) were widowed and $160(64 \%)$ were married, out of which $12(75 \%)$, 5(71.42\%), $45(67.16 \%)$ and $123(76.87 \%)$ were compliant respectively. (Table 5) marital status had no significant role in compliance $(\mathrm{p} \geq 0.01)$.

Table 5

\begin{tabular}{|c|c|c|c|}
\hline Marital status & Total & Compliant & Non-Compliant \\
\hline Single & $16(6.4 \%)$ & $12(75 \%)$ & $4(25 \%)$ \\
\hline Divorced & $7(2.8 \%)$ & $5(71.42 \%)$ & $2(28.57 \%)$ \\
\hline Widowed & $67(26.8 \%)$ & $45(67.16 \%)$ & $22(32.83 \%)$ \\
\hline Married & $160(64 \%)$ & $123(76.87 \%)$ & $37(23.12 \%)$ \\
\hline
\end{tabular}

Of the 250 patients,234(93.6\%) had $\leq 4$ members in their family and $175(74.78 \%)$ of them were compliant.16(6.4\%) had 5-8 members in their family and of these 10(62.5\%) were compliant. The data had no significance on statistical analysis. $(\mathrm{p} \geq 0.01)$

231(92.4\%) subjects reported support from family and friends out of which 176 (76.19\%)were compliant .Only $9(47.36 \%)$ out of $19(7.6 \%)$ who reported there was no support was compliant to the therapy(Table 6,Figure 4).Significant association was noted between compliance and support the subjects get from the family and friends. $(\mathrm{p}<0.01)$

Table 6

\begin{tabular}{|c|c|c|c|}
\hline & $\begin{array}{c}\text { Support from family / } \\
\text { friends }\end{array}$ & \multirow{2}{*}{ Compliant } & $\begin{array}{c}\text { Non- } \\
\text { Compliant }\end{array}$ \\
\cline { 2 - 3 } & Total & $176(76.19 \%)$ & $55(23.80 \%)$ \\
\hline Yes & $231(92.4 \%)$ & $9(47.36 \%)$ & $10(52.63 \%)$ \\
\hline No & $19(7.6 \%)$ & & \\
\hline & $\mathrm{P}<0.01$ & & \\
\hline
\end{tabular}




\section{International Journal of Science and Research (IJSR) \\ ISSN (Online): 2319-7064}

Index Copernicus Value (2013): 6.14 | Impact Factor (2015): 6.391

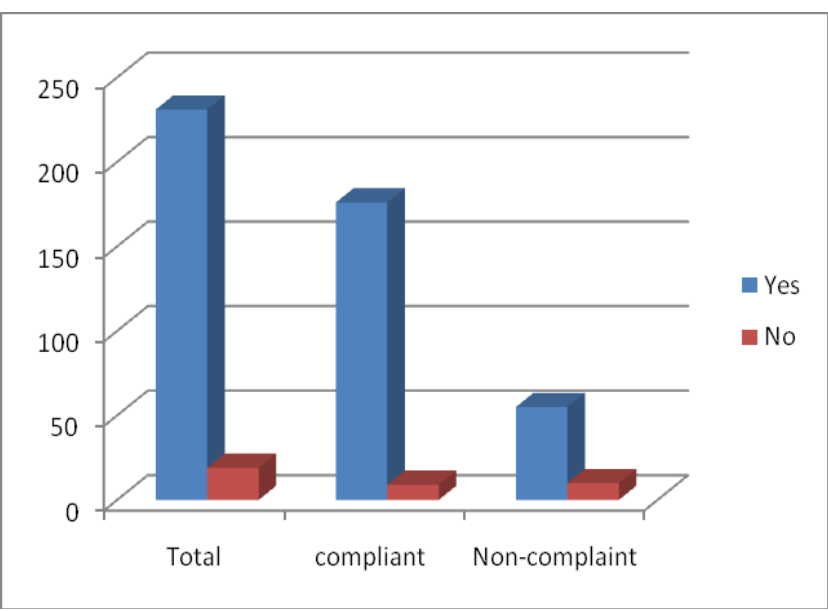

Figure 4

48(19.2\%) subjects had yet another member in the family affected and receiving ART. 42(87.5\%) were compliant in this group. Out of the rest 202(80.8\%),compliance of only $143(70.79 \%)$ is reported (Table 7,Figure 5).compliance is better when another family member received ART $(\mathrm{p}<0.01)$.

Table 7: Any other family member on ART?

\begin{tabular}{|l|c|c|c|}
\hline & Total & Compliant & Non-Compliant \\
\hline Yes & $48(19.2 \%)$ & $42(87.5 \%)$ & $6(12.5 \%)$ \\
\hline No & $202(80.8 \%)$ & $143(70.7 \%)$ & $59(29.21 \%)$ \\
\hline & & $\mathrm{P}<0.01$ & \\
\hline
\end{tabular}

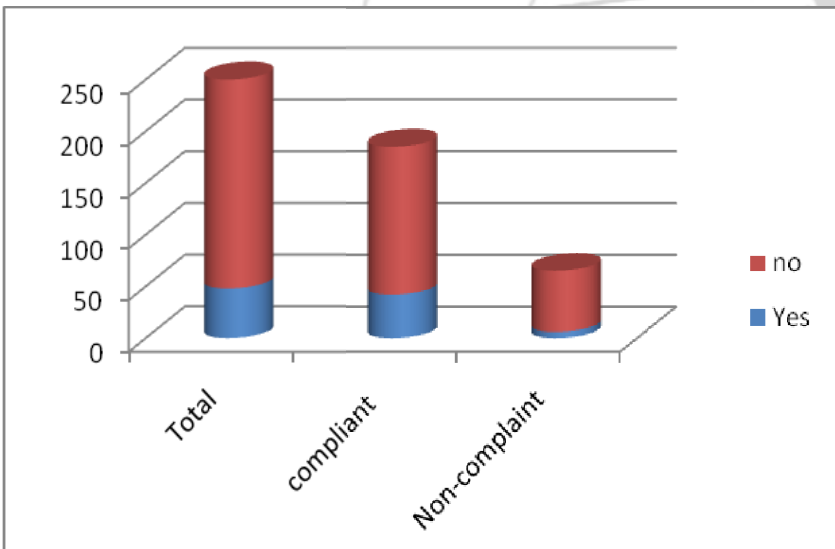

Figure 5

Reminders from family members were there for $187(74.8 \%)$ subjects of which $152(81.28 \%)$ were compliant. Out of the $63(25.2 \%)$ those who had no reminders only 33(52.38\%) were compliant (Table 8,Figure 6). Remainders had improved the adherence rate $(\mathrm{p}<0.001)$.

Table 8:

\begin{tabular}{|c|c|c|c|}
\hline $\begin{array}{c}\text { Reminders from } \\
\text { family }\end{array}$ & Total & Compliant & Non-Compliant \\
\hline Yes & $187(74.8 \%)$ & $152(81.28 \%)$ & $35(18.71 \%)$ \\
\hline No & $63(25.2 \%)$ & $33(52.38 \%)$ & $30(47.61 \%)$ \\
\hline & & $\mathrm{P}<0.001$ & \\
\hline
\end{tabular}

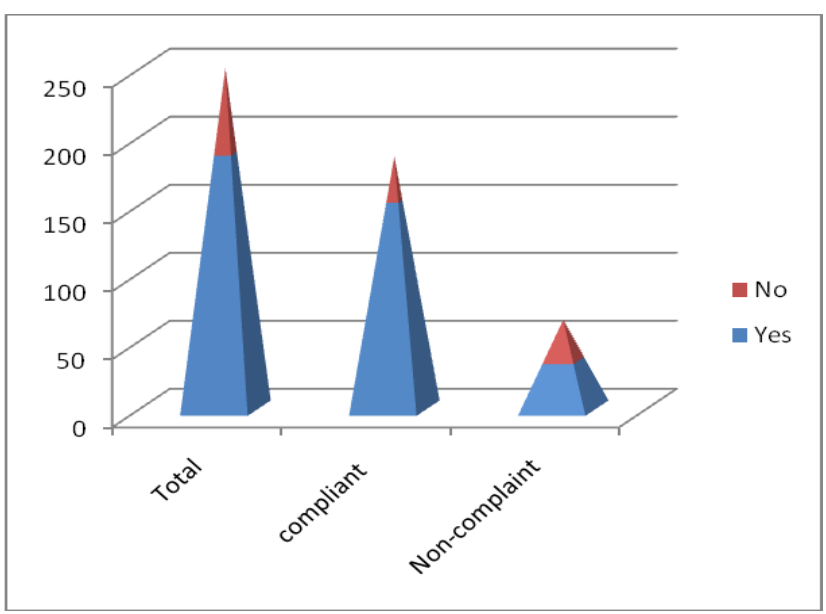

Figure 6

Of the 226(90.4\% )subjects who were satisfied with counselling, $179(79.20 \%)$ were compliant and of the 24(9.6\%)who were not satisfied with the counselling $18(75 \%)$ were noncompliant and only 6(25\%) were compliant(Table 9,Figure 7). Counselling had significant positive impact on compliance $(\mathrm{p}<0.001)$

Table 8

\begin{tabular}{|c|c|c|c|}
\hline $\begin{array}{c}\text { Reminders from } \\
\text { family }\end{array}$ & Total & Compliant & Non-Compliant \\
\hline Yes & $187(74.8 \%)$ & $152(81.28 \%)$ & $35(18.71 \%)$ \\
\hline No & $63(25.2 \%)$ & $33(52.38 \%)$ & $30(47.61 \%)$ \\
\hline & & $\mathrm{P}<0.001$ & \\
\hline
\end{tabular}

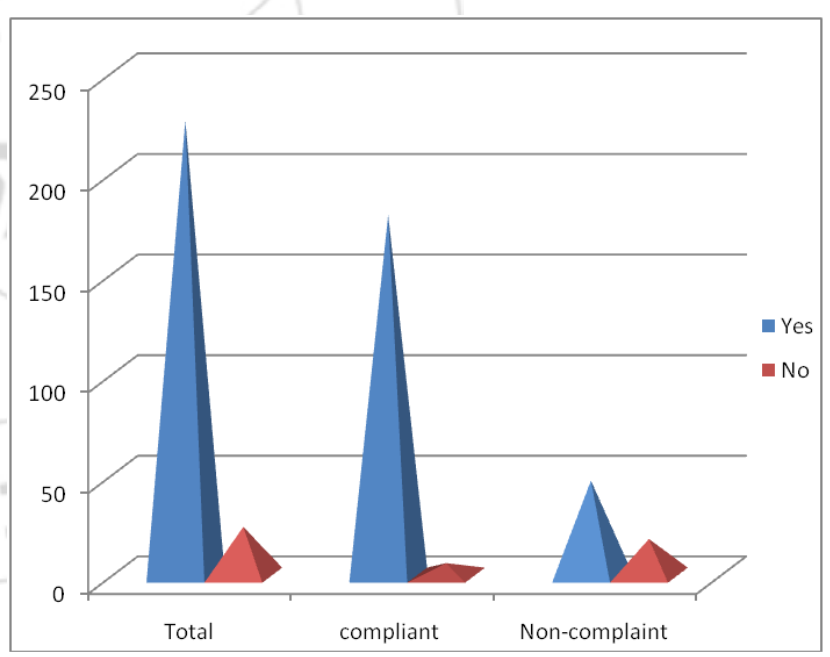

Figure 7: Counselling Satisfaction

Of the 58(23.2\%) patients who has been on ART for <2years,27(46.55\%) have been found to be compliant.154(61.6\%) patients were on ART for a period of 2-5 years of which $124(80.51 \%)$ were found compliant.Of the $38(15.2 \%)$ who were on ART for $>5$ years,34(89.47\%) were compliant(Table 10,Figure 8).compliance rate was high when patients were on ART for a long time $(\mathrm{P}<0.001)$.

Table 10

\begin{tabular}{|c|c|c|c|}
\hline & Total & Compliant & Non-Compliant \\
\hline$<2$ & $58(23.2 \%)$ & $27(46.55 \%)$ & $31(53.44 \%)$ \\
\hline $2-5$ & $154(61.6 \%)$ & $124(80.51 \%)$ & $30(19.48 \%)$ \\
\hline$>5$ & $38(15.2 \%)$ & $34(89.47 \%)$ & $4(10.52 \%)$ \\
\hline & $\mathrm{P}<0.001$ & & \\
\hline
\end{tabular}




\section{International Journal of Science and Research (IJSR) \\ ISSN (Online): 2319-7064}

Index Copernicus Value (2013): 6.14 | Impact Factor (2015): 6.391

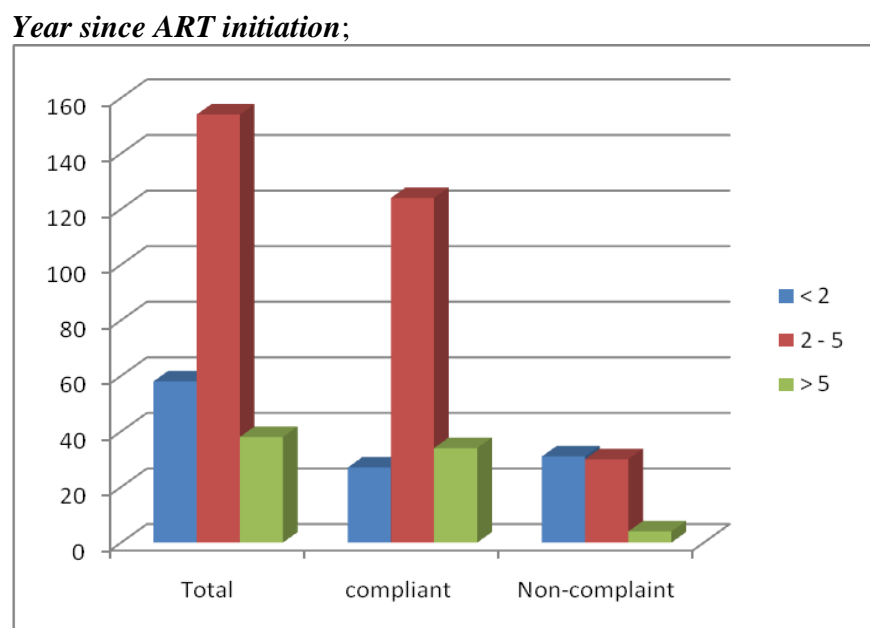

Figure 8

123(49.2\%)patients received Regimen A (Stavudine + Lamivudine + Nevirapine) and $111(\mathbf{9 0 . 2 4 \% )}$ out of it were compliant.Of the $127(50.8 \%)$ who received the Regimen B (Zidovudine + Lamivudine + Nevirapine) ,only 74 $\mathbf{( 5 8 . 2 6 \% ) w e r e ~ c o m p l i a n t ( T a b l e ~ 1 1 , F i g u r e ~ 9 ) . M o r e ~}$ compliance was noted in patients receiving Regimen A $(\mathrm{p}<0.001)$

Table 11

\begin{tabular}{|c|c|c|c|}
\hline Regimen & Total & Compliant & Non-Compliant \\
\hline A & $123(49.2 \%)$ & $111(90.24 \%)$ & $12(19.76 \%)$ \\
\hline B & $127(50.8 \%)$ & $74(58.26 \%)$ & $53(41.73 \%)$ \\
\hline
\end{tabular}

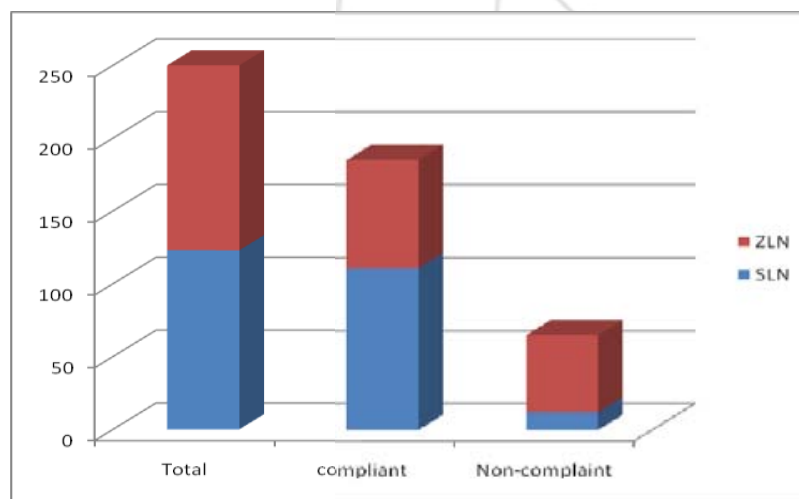

Figure 9

It has been observed that of the 192(76.8\%) patients who were regular in follow up visits,183(95.31\%) were compliant.Only $2(3.44 \%)$ out of $58(23.2 \%)$ patients who were not regular in follow up were compliant(Table 12,Figure 10). Patients with regular follow up were more complaint $(\mathrm{p}<0.001)$.

Table 11

\begin{tabular}{|c|c|c|c|}
\hline Regular follow up & Total & Compliant & Non-Compliant \\
\hline Yes & $192(76.8 \%)$ & $183(95.31 \%)$ & $9(4.68 \%)$ \\
\hline No & $58(23.2 \%)$ & $2(3.44 \%)$ & $56(96.55 \%)$ \\
\hline & & $\mathrm{P}<0.001$ & \\
\hline
\end{tabular}

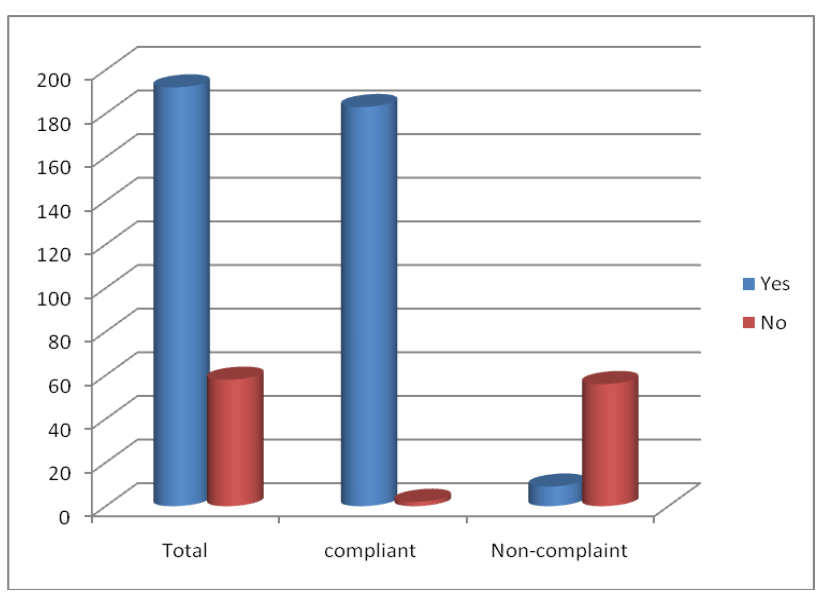

Figure 10: Regular follow up

Of the 54(21.6\%) who have acquired Tuberculosis after the initiation of ART,26(48.14\%) were compliant and 28(51.85\%) were noncompliant.Of the 250,7(2.8\%) patients have seeked Alternative health care but even then 6(85.71\%) of them reported being compliant.

\section{Discussion}

250 HIV patients on ART who had agreed to give consent were interviewed using a questionnaire and their compliance level to the therapy was analysed. The compliance level of $74 \%$ obtained through the study is in concurrence with a study conducted on private clinics in Mumbai (13), where $73 \%$ adherence was reported. Compliance level is comparatively less than a study conducted in Brazil (6) where $89.3 \%$ self reported $100 \%$ compliance. Compliance level is comparable to a study conducted in Bangalore, India (9) where only $60.4 \%$ compliance was reported.

The younger and older age groups were more compliant than the middle aged ones The middle age groups after becoming healthy due to the therapy become over confident and start giving less importance to the therapy without knowing the future complications. This is also supported by a study conducted in Canada(11).

. The subjects who came from nearby places were found more compliant than the subjects from farther places. If any other member of the family is affected by HIV and is receiving ART, there is a greater chance for the patient to become adherent(87.5\%).Chi-square test has shown significant association for the above statement. Support from the family members and their knowedge about the disease had a significant association(76.19\%). As expected, smoking, alcohol ,use of illicit drugs etc affected compliance to a great extend. This relation is also shown in the study conducted by Gutierrez etal in Brazil(6).

The subjects receiving Regimen B were less compliant as compared to the patients on Regimen A had been proved to have greater side effects.The side effects reported by the patients included nausea, vomiting, dry tongue , sleeplessness ,dizziness, allergic reactions, joint pain,weight loss, skin lesions,stomach burn,anorexia,tortuousvein,renal stones,blisters in tongue,itching, diarrhoea,muscle pain , dyspnoea , anemia , loss of vision, numbness etc. The 


\section{International Journal of Science and Research (IJSR) \\ ISSN (Online): 2319-7064 \\ Index Copernicus Value (2013): 6.14 | Impact Factor (2015): 6.391}

majority of the patients said that these were more common during the initial years of starting of the drug. This was also found to have a significant association with the compliance of the patients.In this study also,patients on ART for less than 2 years were less compliant.

Similarly when the patient has been receiving the ART for a longer time their compliance is more. This is in conflict to the study from Banglore(9) where no such trends were observed .The reason for high compliance in patients who has been on ART for a longer time(89.47\%->5years) is that they get adapted to the drug and the side effects would have become unnoticed.

The patients who were attending the follow up dates regularly were found more compliant Counselling satisfaction is found to be yet another important determining factor for compliance

In contrast to the expectations, educational status , employment status, family size, marital status and economic status were not found to be determining factors for compliance..The other reasons that were pointed out were forgetfulness, going to far off places for work ,poverty etc .An important thing to be noted here is that only a negligible percentage of patients reported side effects of the drug as a reason for non compliance.

\section{Conclusion}

The study revealed that compliance is affected by a number of socio-economic as well as physical reasons .Many demographic factors were found significantly associated with the compliance. The study revealed that age, distance travelled from the ART centre, family support, other family members in ART, reminders, counselling ,ART duration, regular follow up,side effects, regimen etc had direct effect on determining the compliance of the patient.

The compliance can be increased by Repeated counselling easily accessibility and regimens with less side effects. Proper identification of factors responsible can help in improving the present treatment facility given to the patient so that the compliance can be improved significantly.. The study involved interaction with HIV patients which helped in understanding the various aspects of their living conditions the attitude of the patients towards the therapy and the various complications and the after effects of the therapy can be elicited. Detailed study on the reasons for low compliance can help in determining various measures to alleviate them.

\section{References}

[1] National AIDS Control Organisation (NACO) Annual Report 2011-2012.

[2] Rocha GM,Machado CJ,Acursio FA.Monitoring adherence to ART in Brazil:an urgent challenge.Cad Saude Publica.2011;27(Suppl 1):S67-78.

[3] Sethi AK, Celentano DD, Gange SJ et al: Association between adherence to antiretroviral therapy andhuman immunodeficiency virus drug resistance. Clin Infect Dis2003, 37(8):1112-8.
[4] Donnell D,Baeten JM,Kiarie J,etal.Heterosexual HIV-1 transmission after initiation of ART:a prospective cohort analysis.Lancet.2010;375:2092-2098

[5] Taiwo B.Adherence to ART:The more you look,the more you see.Curr Opin HIV AIDS.2009;4:448-92.

[6] Gutierrez EB,Anamarli CS etal. Measuring adherence to ART.AIDS and Behaviour.2012;16(6):1482-1490.

[7] Schiller DS. Identification, management, and prevention of adverse effects associated withhighly active antiretroviral therapy. Am J Health Syst Pharm 2004.

[8] Lignani L, Greco DB, Carneiro M. Assessment of the compliance to antiretroviral drugs among HIV/AIDS patients. Rev Saude Publica 2001; 35: 495-501.

[9] Mary B Cauldbeck, Catherine O'Connor, Mortimer Betal; Adherence to anti-retroviral therapy among HIV patients in Bangalore, India 2003.

[10]Kalichman SC, Cherry J, Cain D. Nurse-delivered antiretroviral treatment adherence intervention for people with low literacy skills and living with HIV/AIDS. J Assoc NursesAIDS Care 2005; 16: 3-15.

[11] Veinot TC, Flicker SE, Skinner HA, et al. 'Supposed to make you better but it doesn't really': HIV-positive youths' perceptions of HIV treatment. J Adolesc Health 2006; 38: 261-26

[12] Jean B Nachega, Morroni etal.'HIV treatment Adherence, patient Health Literacy'.J Int Assoc Physicians AIDS Care.2012;11(2):128-133.

[13]Bijal Shah, Louise WalsheDattary G. Saple: Adherence to Antiretroviral Therapy and Virologic Suppression among HIV-Infected Persons Receiving Care in Private Clinics in Mumbai, India. Clin Infect Dis2007,44:123544. 